placing the needle at the periosteum level, approximately $5 \mathrm{~mm}$ below the papilla. The 30G, $9 \mathrm{~mm}$ length needle is short, sharp, and strong (Septoject Evolution, Septodont). Occasionally the needle will penetrate the cortical plate, but this is not necessary, or desirable.

As well as being conservative of LA solution, the area of tissue anaesthetised is relatively localised and the tongue is left un-anaesthetised, enabling restorative procedures in the same appointment on both lower quadrants, without bilateral IANBs. The patient can immediately assess the smoothness of a recently placed restoration with their tongue. An advantage over, say, the Stabident system, ${ }^{4}$ or a computercontrolled LA delivery system such as The Wand, is that it does not involve the purchase of any special equipment. I have used this technique for all routine restorative procedures: restorations, root canal treatments, and even extractions in the posterior mandible (administering an adjunctive lingual infiltration of articaine 4\%).

A disadvantage is the potential for increased frequency of administration of the LA solution into the circulatory system but this has happened surprisingly infrequently. A retrospective audit of this technique in my practice involved 110 administrations with only one failure to gain satisfactory anaesthesia, in a patient with an irreversible pulpitis requiring root treatment on a lower molar. There was one incident of inadvertent administration of anaesthetic solution into the circulatory system.

This technique has proved an important addition to my skill set and has not only saved time and given much more predictable anaesthetic results; it has also been greatly welcomed by my patients.

D. Miller

London

1. Malamed SF. Is the mandibular nerve block passé? J Am Dent Assoc 2011; 142 Suppl 3: 3S-7S.

2. Pogrel M A. Permanent nerve damage from inferior alveolar nerve blocks: a current update. J Calif Dent Assoc 2012; 40: 795-797.

DOI: 10.1038/sj.bdj.2013.751

\section{TOGETHER WE ARE STRONGER}

Sir, I write regarding the recent letter from N. Knott (BDJ 2013; 215: 607).
In his letter Dr Knott says he was a member of a small minority opposed to the BDA being a trade union in 1975 when he was a member of the Representative Board.

I would suggest that minority may even be smaller in the profession now.

The trade union activity of the profession is incredibly important to preserve the ethical position of the profession as it comes under more and more influence from outside agencies and politicians; indeed the role of the new PEC is to ensure that these changes are vigorously challenged when they impinge on the professional and ethical manner in ways colleagues practise.

Now is a time when that strength of membership is needed more than ever to ensure that colleagues are supported through all aspects of their career to provide quality ethical treatment for our patients. It is very evident that with recent scandals about CQC, Mid Staffs and others that the restructuring of the NHS allows political leaders to shift blame to others, and the Francis report has been extensively discussed within the BDA to ensure we drive the profession in clinical standards and oppose things that impinge on that.

With the advance of a new NHS contract, and the implications of care pathways, best practice and levels of competency of the profession in proposed three tier levels of skills, it is imperative to be part of a solid and robust trade union to ensure our professional ethics and our ability to provide a wide range of treatments are defended. These changes will have impact across the whole profession and not just those working within the NHS.

If you have not joined the BDA for its trade union function, do so please to ensure that together we are stronger.

E. Crouch

PEC Member

DOI: 10.1038/sj.bdj.2013.752

\section{ENTERTAINMENT VS. EDUCATION}

Sir, the influence of media on public health is significant and has great potential for the positive. Unfortunately, I feel this is not always used to the utmost benefit. In a recent episode
(28 May 2013) of Embarrassing Bodies: Live from the Clinic, I was left disappointed with the lack of attention paid to periodontal disease, the leading cause of tooth loss worldwide. ${ }^{1}$

Simone, a 44-year-old female patient, presented via webcam with the complaint of 'receding gums' and being unable to tolerate her current denture for longer than an hour, due to swelling of the gums. She had a history of recent trauma causing greater tooth loss. The patient's primary concern was a possible allergy to the denture.

Following this, the advice provided focussed on the possibility of an illfitting denture or allergy. The options of dental implants were even suggested. I felt there was an undue concentration on the more 'sexy' aspects of the case, providing television entertainment rather than informative education. The crux of Simone's problems stemmed from her 'receding gums', indicating periodontitis, of which she appeared unaware and naive. There was no acknowledgement of this, or that simple measures such as good oral hygiene, healthy life choices, and regular dental visits are crucial in the management of this common condition.

Addressing patient concerns is, rightly so, a fundamental issue in dentistry and in the case of Simone the denture did need to be carefully assessed. However, I would have liked to have seen this show, which has had viewer ratings as high as 3.5 million $^{2}$ and is ostensibly considered a more authoritative medical-based television production, taking a more responsible attitude towards public health awareness. The provision of accurate, up-todate and simple advice about some of the most common issues in dentistry is vital in raising awareness of problems seen daily in practice.

A. Morris Cardiff

1. Darveau R P. Periodontitis: a polymicrobial disruption of host homeostasis. Nat Rev Microbiol 2010; 8: 482-490.

2. Plunkett J. Embarrassing Bodies in peak shape with $3.5 \mathrm{~m}$ viewers. The Guardian 31 January 2011. Available at: www.guardian.co.uk/media/2011/ jan/31/tv-ratings-embarrassing-bodies-channel4 (accessed 29 July 2013).

DOI: 10.1038/sj.bdj.2013.753 